\title{
Temperature effect on graphene strength
}

\author{
A.M. Iskandarov ${ }^{1,2, \dagger}$, Y. Umeno ${ }^{1}$, S.V. Dmitriev ${ }^{2}$ \\ †a.iskandarov@gmail.com \\ ${ }^{1}$ Institute of Industrial Science, The University of Tokyo, 4-6-1 Komaba, Meguro-ku, Tokyo, Japan 153-8505 \\ ${ }^{2}$ Institute for Metals Superplasticity Problems RAS, Khalturin St. 39, 450001 Ufa
}

\section{Влияние температуры на прочность графена}

\author{
Искандаров А.М., ${ }^{1,2}$, Умено Ё. ${ }^{1}$, Дмитриев С.В. ${ }^{2}$ \\ ${ }^{1}$ Institute of Industrial Science, The University of Tokyo, 4-6-1 Komaba, Meguro-ku, Tokyo, Japan 153-8505 \\ ${ }^{2}$ Институт проблем сверхпластичности металлов РАН, ул. Халтурина 39, Уфа 450001
}

The effect of temperature on the strength of strained graphene is studied by means of molecular dynamics simulations. Initially strained graphene is heated with constant temperature increase rate from $0 \mathrm{~K}$ up to the mechanical instability and fracture. Strong influence of the temperature increase rate on the critical temperature has been revealed, which is an expected effect in the simulations of fracture triggered by thermal fluctuations. For uniaxial tension along zigzag (armchair) direction the critical strain at room temperature is equal to $0.22(0.19)$, while at zero temperature the critical strain is equal to $0.30(0.23)$. Hydrostatic tension at zero temperature results in graphene fracture at strain of 0.23 , while at room temperature at strain of 0.16 .

Keywords: graphene, stability, strength, temperature effect.

\section{Introduction}

Graphene is a two-dimensional crystalline material whose structure is a monoatomic sheet of carbon atoms packed in the form of a honeycomb lattice, with each atom having three nearest neighbors, as shown in Fig. 1. Unusual structure and properties of graphene attract an interest from the viewpoint of basic as well as applied science. Though nowadays graphene is still too expensive to be produced for commercial needs, it is believed that in the coming years it will be developed for many different applications such as optics [1], spintronics [2], hydrogen storage [3], composite materials [4], etc.

Graphene is the strongest and the most stretchable known material. The effect of elastic strain on mechanical
Методом молекулярной динамики изучено влияние температуры на прочность графена. Нагрев графена, подвергнутого деформации одноосного или двухосного растяжения, производился с постоянной скоростью роста температуры до момента разрыва. Показано, что скорость роста температуры оказывает сильное влияние на критическую температуру, что является вполне естественным при моделировании термоактивированных процессов разрушения. Для одноосного растяжения вдоль направления зигзаг (кресло) при комнатной температуре критическое значение деформации составило $0,22(0,19)$, в то время как при нулевой температуре разрыв происходит при деформации $0,30(0,23)$. При гидростатическом растяжении при нулевой температуре критическая деформация равна 0,23 , а при комнатной температуре 0,16 .

Ключевые слова: графен, устойчивость, прочность, температурный эффект.

and physical properties of graphene and other nanoscale carbon polymorphs has recently been addressed, and these investigations are in line with the elastic strain engineering, a rapidly developing branch of materials science [5]. Elastic strain engineering is a promising way to modify and control properties of nanomaterials. Strength of nanomaterials can approach the theoretical limit, and they can sustain elastic strain of order of 0.01 or even 0.1 before fracture or structural transformations take place. Considerable change of interatomic distances and crystal lattice symmetry at such a large elastic strain can result in appearance of very unusual mechanical, thermal, optic, electric, magnetic, and other properties of materials.

For example, it was found that thermal conductivity of graphene and carbon nanotubes monotonously decreases 
with the growth of tensile stress [6]. Optical conductivity of graphene is also very sensitive to the applied stress [7]. In Raman spectroscopy of optical vibrational modes of graphene it was found that uniaxial tension results in a considerable red shift of the lines $\mathrm{G}$ and $2 \mathrm{D}$ and in splitting of the line $G$ into two lines due to the straininduced reduction of symmetry [8]. First-principle calculations show that uniaxial strain up to 0.1 does not produce a gap in the electron density states [9], and that uniaxial strain of order of 0.2 can be achieved [10]. Experimental estimation of the strength of graphene gave a remarkably high value of $42 \mathrm{~N} / \mathrm{m}$ [11]. An increase of the Young modulus of graphene with temperature in the temperature range from $100 \mathrm{~K}$ to $500 \mathrm{~K}$ was observed in a molecular dynamics study [12]. A nonlinear elastic theory of graphene was considered in [13]. Linear and nonlinear stiffness constants of graphene were estimated from the empirical interatomic potentials [14]. Another version of nonlinear elasticity theory of graphene was proposed in Ref. [15], where the authors compare their theoretical stress-strain curves with experimental data in a wide range of elastic strain, up to 0.3 . Propagation of solitons in graphene nanoribbons has been investigated in [16].

Ideal strength of graphene has been studied by atomistic simulations at zero temperature and the border of stability has been found in the three-dimensional strain space $\left(\varepsilon_{x x}, \varepsilon_{y y}, \varepsilon_{x y}\right)$ [16-18]. Since devices are typically used and experiments are often carried out at room temperature or even at higher temperatures, it is important to understand the effect of temperature on properties of graphene, especially on its strength, in order to predict a range of possible applications. It is well known that typically temperature decreases strength of materials [19]. It is thus important to know the temperature that can be sustained by graphene layer strained to a certain level.

In the present study we show relation between critical temperature of graphene layer and applied strain. We also investigate the effect of heating rate on the critical temperature at given strain.

\section{Methods}

For our study we use molecular dynamics simulations with interatomic potential developed by Brenner et al. For this potential primitive cell's translation vectors of unstrained graphene at $0 \mathrm{~K}$ can be defined by two vectors, viz. $a_{1}\left(\sqrt{3} \rho_{0}, 0\right)$ and $a_{2}\left(\sqrt{3} \rho_{0} / 2,3 \rho_{0} / 2\right)$ (see Fig. 1$)$, where $\rho_{0}=$ $1.4505 \AA$ is the bond length. Primitive cell contains two

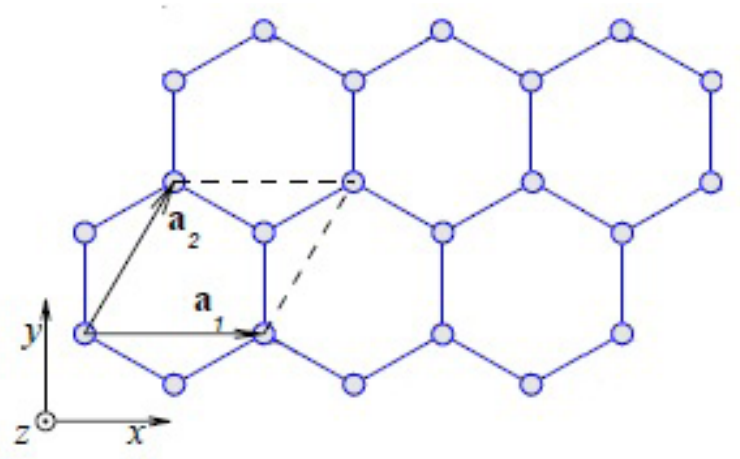

Fig. 1. Structure of flat graphene. Primitive cell translation vectors are $a_{1}$ and $a_{2}$. atoms which in unstrained graphene are located in positions given by the sublattice shift vectors $s_{1}(0,0)$ and $s_{2}\left(\sqrt{3} \rho_{0}, \rho_{0}\right)$. One can see that the coordinate system is chosen in a way that the zigzag (armchair) direction is along the abscissa (ordinate).

However, in our study flat graphene is subjected to in-plane strain with the components $\left(\varepsilon_{x x}, \varepsilon_{y y}\right)$ which causes new equilibrium positions of atoms in primitive cell. To find these equilibrium positions we performed relaxation of primitive cell for each applied strain, then simulation cell was built by replication of primitive cell along $x$ - and $y$ - directions. Simulation cell was subjected to periodic boundary conditions along $x$ - and $y$-directions and its size was kept constant during simulation.

Three types of straining are considered: (i) uniaxial tension along zigzag direction, $\varepsilon_{x x}>0$, (ii) uniaxial tension along armchair direction, $\varepsilon_{y}>0$, (iii) hydrostatic tension, $\varepsilon_{x x}=\varepsilon_{y y}>0$. In this work we focus on relatively large values of strain applied to graphene. In this case the instability happens at rather small temperatures and it is triggered by local bond breaking and further propagation of nucleated cracks, while in the case of small strains and, consequently, large critical temperatures instability is assisted by phase-transition like increase of homogeneous disorder, which in the limit of unstrained graphene defines its melting temperature.

In order to find critical temperature for each applied strain we increase temperature linearly from $0 \mathrm{~K}$ up to the moment, when mechanical instability occurs immediately followed by crack nucleation and propagation. The heating rate was chosen in a way to obtain approximately same waiting time $(\tau)$ for the instability event. To demonstrate the effect of the waiting time on the critical temperature we fixed $\varepsilon_{x x}=0.19$ and considered $\tau=2.0,4.7$, $6.6,9.6,29.0,56.5 \mathrm{ps}$.

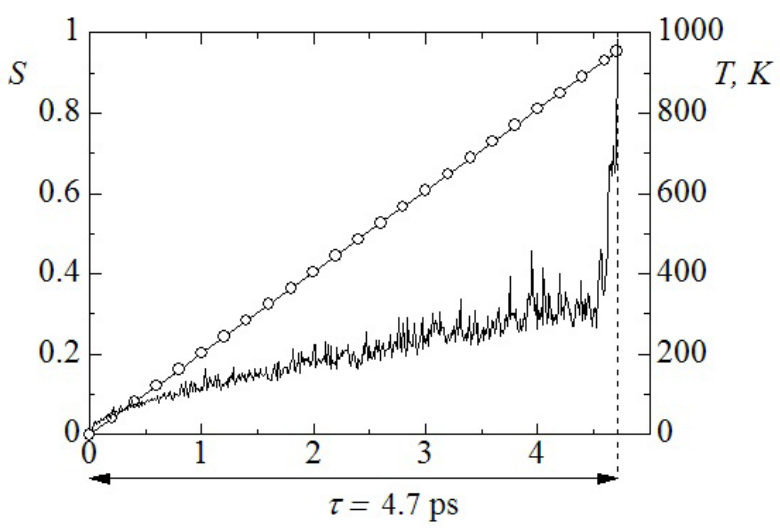

Fig. 2. Time evolution of graphene temperature, $T$, (open circles) and maximal displacement of atoms, $S$, (solid line) up to the instability event at $\tau=4.7 \mathrm{ps}$.

As a criterion of instability we use sudden increase of maximal displacement of atoms from their lattice positions $(S)$. Typical time evolution of $S$ for the case of $\varepsilon_{x x}=0.19$ and $\tau=4.7$ ps is shown in Fig. 2, where we also show temperature $(T)$ as the function of time by solid line with open circles. 
Because of the probabilistic nature of instability and scatter of results imposed by elevated temperature we perform several simulations for each strain in order to get averaged values of critical temperature.

Temperature of grapheme is related to the average kinetic energy per atom, $K$, as follows

$$
T=2 K / 3 k_{b} \text {, }
$$

where $k_{b}=8.617 \times 10^{-5} \mathrm{eV} \cdot \mathrm{K}^{-1}$ is the Boltzmann constant. Simulation results and their discussion are presented in the following section.

\section{Results and discussion}

The relations between critical temperature and applied strain are shown in Fig. 3 for the three types of straining, (a) $\varepsilon_{x x}>0$, (b) $\varepsilon_{y y}>0$, (c) $\varepsilon_{x x}=\varepsilon_{y y}>0$. Note that the logarithmic scale is used for temperature. Abscissa in all figures varies up to the corresponding critical strain, when mechanical instability occurs at $0 \mathrm{~K}$.

The corresponding values of critical strain are 0.23 in (a), 0.3 in (b), and 0.23 in (c). These results are in very good agreement with the edge of stability region reported in [16-
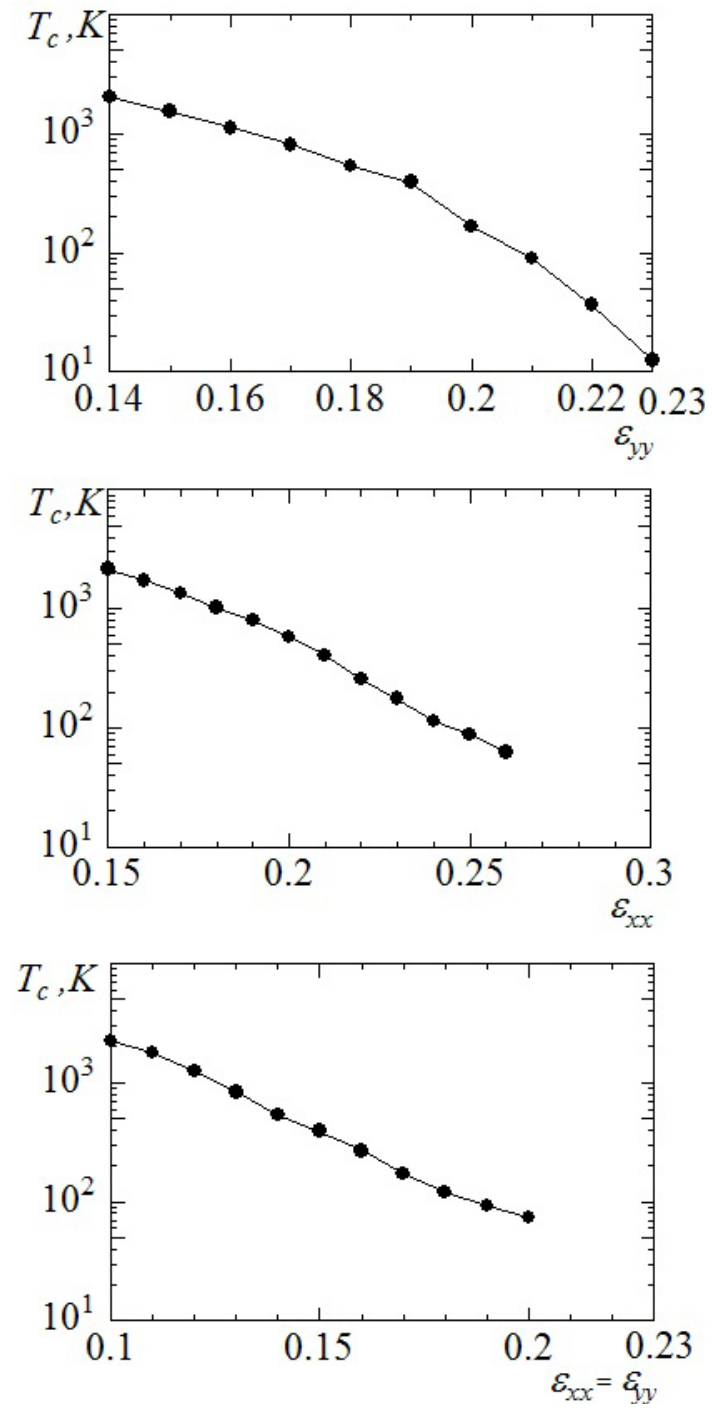

Fig. 3. Critical temperature, Tc, as a function of applied strain for three deformation modes: (a) $\varepsilon_{x x}=0.0$, (b) $\varepsilon_{y y}=0.0$, (c) $\varepsilon_{x x}=\varepsilon_{y y^{\circ}}$ Logarithmic scale is used for ordinate.
18]. One can see from Fig.3 that the logarithm of the critical temperature for all deformation modes decreases almost linearly with increase of applied strain meaning that critical temperature decreases exponentially with increase in elastic strain. Fig. 3. can also be used for estimating stability region for each particular temperature, i.e. smaller stability region corresponds to higher temperature for all deformations modes.

However, our investigation of the effect of waiting time shows that critical temperature for each particular strain depends on the waiting time $\tau$. Indeed, Fig. 4 shows relation between critical temperature $T_{c}$ and $\tau$. Decrease of waiting time causes increase of critical temperature. We attribute this effect to the probabilistic nature of mechanical instability at finite temperature. The probability of instability event is nonzero (can be negligibly small though) at elevated temperature for any applied strain and the longer time of monitoring is the higher this probability is.

One can also see from Fig. 4 that for $\tau>30$ ps critical temperature depends weakly on $\tau$ which means that there is a saturation of critical temperature as the function of waiting time. The latter means that the critical temperature for large $\tau$ can be predicted with good accuracy from is values for rather small values of $\tau$ that can be obtained within reasonable computation time.

\section{Conclusions}

We performed molecular dynamics simulations of monoatomic layer of graphene in order to find relation between critical temperature and applied strain. Critical temperature was found to decrease exponentially with applied strain in the range of large strains where critical temperature is relatively small.

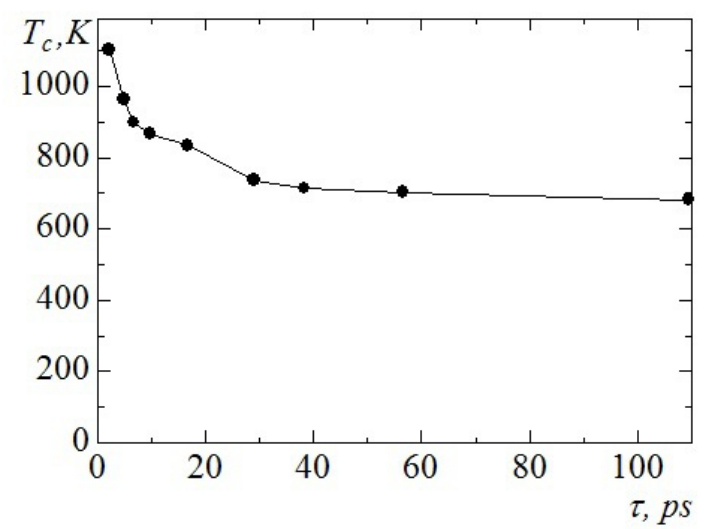

Fig. 4. Critical temperature, $T$, as a function of waiting time for the case of uniaxial strain $\varepsilon_{x x}=0.19$ applied along the zigzag direction.

Influence of heating rate on critical temperature has been revealed; for small waiting times there is significant decrease of critical temperature, while for large waiting times we observe convergence of critical temperature.

It was found that for uniaxial tension along zigzag (armchair) direction the critical strain at room temperature is equal to $0.22(0.19)$, while at zero temperature the critical strain is equal to $0.30(0.23)$. Hydrostatic tension 
at zero temperature results in graphene fracture at strain of 0.23 , while at room temperature at strain of 0.16 . The reduction of critical strain at room temperature in comparison with that at $0 \mathrm{~K}$ comprises $20-30 \%$.

\section{References}

1. C. Soldano, A. Mahmood, E. Dujardin, Carbon 48, 2127(2010).

2. N. Tombros, C. Jozsa, M. Popinciuc, H.T. Jonkman, B.J.van Wees, Nature 448, 571 (2007).

3. D.C. Elias, R.R. Nair, T.M.G. Mohiuddin, S.V. Morozov, P. Blake, M.P. Halsall, A.C. Ferrari, D.W. Boukhvalov, M.I. Katsnelson, A.K.G. Heim, K.S. Novoselov, Science 323, 610 (2009);

4. J.O. Sofo, A.S. Chaudhari, G.D. Barber,Phys. Rev. B 75 , 153401 (2007).

5. S. Stankovich, D.A. Dikin, G.H.B. Dommett, K.M. Kohlhaas, E.J. Zimney, E.A. Stach, R.D. Piner, S.T. Nguyen, R.S. Ruoff, Nature 442, 282 (2006).

6. T. Zhu, J. Li, Progr. Mater. Sci. 55, 710 (2010). X. Li, K. Maute, M.L. Dunn, R. Yang, Phys. Rev. B. 81,245318 (2010).

7. F.M.D. Pellegrino, G.G.N. Angilella, R. Pucci, Phys. Rev. B 81, 035411 (2010).

8. M. Huang, H. Yan, C. Chen, D. Song, T.F. Heinz, and J. Hone, PNAS 106, 7304 (2009).

9. R.M. Ribeiro, V.M. Pereira, N.M. R. Peres, P.R. Briddon,
A.H. Castro Neto, New Journal of Physics 11, 115002 (2009).

10. F. Liu, P. Ming, J. Li, Phys. Rev. B. 76, 064120 (2007).

11. C. Lee, X. Wei, J.W. Kysar, J. Hone, Science 321, 385 (2008).

12. X. Wei, B. Fragneaud, C. A. Marianetti, J. W. Kysar, Phys. Rev. B. 80, 205407 (2009).

13. J.-W. Jiang, J-S. Wang, B. Li, Phys. Rev. B. 80, 113405 (2009).

14. J.-W. Jiang, J.-S.Wang, B. Li, Phys. Rev. B. 81, 073405 (2010).

15. E.Cadelano, P. L. Palla, S. Giordano, L. Colombo, PRL 102, 235502 (2009).

16. A.V. Savin, Yu.S. Kivshar, Letters on Materials. 1(1), 3 (2011) [Савин А. В., Кившарь Ю.С. Письма о материалах. 1(1), 3 (2011)]

17. S.V. Dmitriev, J.A. Baimova, A.V. Savin, Yu.S. Kivshar JETP Letters. 93(10) 571 (2011).

18. S.V. Dmitriev, J.A. Baimova, A.V. Savin, Yu.S. Kivshar. Comp. Mater. Sci. (2011). doi: 10.1016/j.commatsci.2011.08.019.

19. J.A. Baimova, A.V. Savin, Letters on Materials. 1(3), 171 (2011). [Баимова Ю.А., Савин А. В. Письма о материалах. 1(3), 171 (2011)].

20. A.M. Iskandarov, S.V. Dmitriev, Y. Umeno, JSME (in press) 2011.

21. D.W. Brenner, Phys. Rev. B 42, 9458 (1990). 